\title{
Antibiotic availability and the prevalence of pediatric pneumonia during a physicians' strike
}

\author{
Ken Crocker PhD MD ${ }^{1}$, Benvon Cramer $M D^{2}$, James $M$ Hutchinson $M^{3}$
}

\begin{abstract}
K Crocker, B Cramer, JM Hutchinson. Antibiotic availability and the prevalence of pediatric pneumonia during a physicians' strike. Can J Infect Dis Med Microbiol 2007;18(3):189-192.
\end{abstract}

BACKGROUND: Antibiotics are widely believed to be overprescribed for pediatric respiratory infections, yet there are few data available on the effect of a sudden decrease in antibiotic availability on pediatric infectious disease.

OBJECTIVE: To determine whether the prevalence of radiographically diagnosed pneumonia changed over a period of decreased physician access and decreased antibiotic availability.

DESIGN: A retrospective study was performed which reviewed the number of pediatric respiratory antibiotic prescriptions over a period which included a physicians' strike. The study examined whether antibiotic availability had been affected by the strike. Pediatric chest radiograph reports were reviewed for the same period to determine whether changes in antibiotic availability had affected the prevalence of radiographically diagnosable pneumonias among children presenting to a pediatric emergency room.

RESULTS: While prescriptions for antibiotics fell by a minimum estimate of $28 \%$ during the strike, there was no change in the frequency of radiographic diagnoses of pneumonia.

CONCLUSIONS: Respiratory antibiotics appear to be available in the community in excess of the amount required to control pneumonia. A $28 \%$ decrease in antibiotic availability did not result in a significant increase in respiratory disease.

Key Words: Antibiotics; Chest radiography; Overprescribing; Pediatric pneumonia; Physician strikes

\section{La disponibilité des antibiotiques et la prévalence de pneumonie pédiatrique pendant une grève des médecins}

\begin{abstract}
HISTORIQUE : Il est largement supposé que les antibiotiques sont trop prescrits dans le cadre d'infections respiratoires pédiatriques, mais il existe peu de données sur l'effet d'une diminution soudaine de la disponibilité des antibiotiques sur les maladies infectieuses pédiatriques.

OBJECTIF : Déterminer si la prévalence de pneumonies diagnostiquées par radiographie a changé pendant une période au cours de laquelle l'accès aux médecins était limité et la disponibilité des antibiotiques était réduite. CONCEPTION : On a procédé à une étude rétrospective pour analyser le nombre de prescriptions d'antibiotiques pour des infections respiratoires pédiatriques pendant une période incluant une grève de médecins. L'étude permettait d'évaluer si la disponibilité des antibiotiques diminuait à cause de la grève. On a examiné les résultats des radiographies thoraciques pédiatriques pendant la même période, pour déterminer si des modifications à la disponibilité des antibiotiques influaient sur la prévalence de pneumonies pouvant être diagnostiquées par radiographie chez des enfants consultant à un département d'urgence pédiatrique.

RÉSULTATS : D'après une estimation minimale, les prescriptions d'antibiotiques ont chuté de $28 \%$, pendant la grève, mais la fréquence de diagnostics radiographiques de pneumonie n'a pas changé.

CONCLUSIONS : Il semble y avoir plus d'antibiotiques respiratoires que nécessaire dans la collectivité pour contrôler la pneumonie. Une diminution de $28 \%$ de la disponibilité des antibiotiques n'a pas entraîné d'augmentation significative des infections respiratoires.
\end{abstract}

A ntibiotic utilization in North America is much greater than in other areas of the world (1), and has been implicated in the development of antimicrobial-resistant strains (2). Antibiotics are regarded as being overprescribed for pediatric respiratory infections (3-8), contributing to the problem of antibiotic resistance (5). There is ample evidence comparing microbiological cultures with prescribing practices (9), suggesting that a decrease in antibiotic availability may have limited impact on respiratory disease prevalence; however, this hypothesis has been difficult to test.

Attempts have been made to decrease antibiotic prescription rates through physician and patient education programs (10); however, these studies rarely address resultant changes in disease prevalence. If antibiotics are appropriately prescribed, it would be reasonable to hypothesize that decreased physician access and decreased antibiotic availability would result in detectable changes in the prevalence of community-acquired pneumonia. However, if current antibiotic prescribing practices are excessive, as is widely believed, it may be hypothesized that decreased physician access and decreased antibiotic availability would result in no significant changes in community-acquired pneumonia prevalence.

An opportunity to test these hypotheses presented itself during the Newfoundland and Labrador physicians' strike of October 2002. Over this period, most family practitioners' offices in the St John's area were closed, and pediatric medical services were available only through the Janeway Children's Health and Rehabilitation Centre emergency room. Thus, the strike acted as a 'natural experiment', allowing us to examine whether decreased physician access and decreased antibiotic availability affected the prevalence and severity of pediatric pneumonia. It was hypothesized that the prevalence of pediatric pneumonia would increase if prestrike antibiotic prescribing levels were appropriate, and that the prevalence would not change if antibiotic levels were excessive.

\footnotetext{
${ }^{1}$ Discipline of Radiology, Health Sciences Centre, Memorial University of Newfoundland; 'Janeway Children's Health and Rehabilitation Centre;

${ }^{3}$ Division of Medical and Clinical Epidemiology, Faculty of Medicine, Memorial University of Newfoundland, St John's, Newfoundland

Correspondence: Dr Ken Crocker, Discipline of Radiology, Health Sciences Centre, Memorial University of Newfoundland, St John's,

Newfoundland A1B 3V6. Telephone 709-777-6034, fax 709-777-4472, e-mail ken.crocker@yahoo.com

Received for publication September 6, 2005. Accepted January 29, 2007
} 


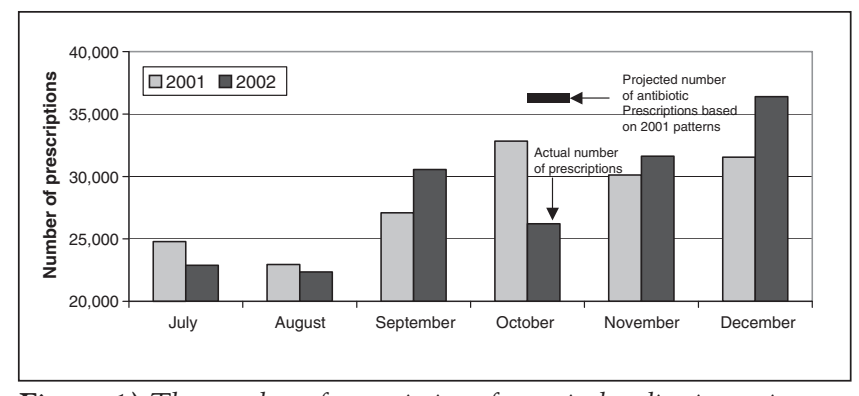

Figure 1) The number of prescriptions for typical pediatric respiratory antibiotics in Newfoundland and Labrador between 2001 and 2002. The Newfoundland and Labrador physicians strike occurred over the first three weeks of October 2002. The dark bar indicates the number of prescriptions projected to have been written had there not been a strike, based on the fall 2001 patterns and ratios of the number of prescriptions written between the two years. Actual prescriptions are $28 \%$ below estimated levels. Note that the data cover the entire month, while the strike lasted three weeks, thus underestimating the drop in prescriptions during the strike

There is sparse literature addressing the effects of physician strikes on indicators of health. To date, some findings are: an increase in hypertension prevalence among affluent males (11), an increase in cesarean sections within a context of unchanging perinatal mortality (12), and a decrease in 'colds' and 'abdominal pains' as presenting complaints (13). Death rates have also been investigated and have not been seen to increase $(14,15)$. Overall, health care utilization patterns and outcomes do not appear to change substantially during strikes (16).

It is not clear what effect decreased access to family physicians has on the prevalence of infectious disease. The present study attempted to assess the effect of the physicians' strike on antibiotic availability and correlate changes in the prevalence of radiographically diagnosable pediatric pneumonia.

\section{METHODS}

Physicians in Newfoundland and Labrador went on strike from October 1, 2002, to October 17, 2002. Most physician services had returned to normal operations by October 20, 2002. All reports of radiographs ordered through the Janeway Children's Health and Rehabilitation Centre emergency room were reviewed for the period between September 9, 2002, and November 10, 2002. This included the strike period as well as three weeks before and after the strike. Studies ordered for nonrespiratory complaints (such as trauma) were excluded from the study, while reports of studies for possible respiratory ailments (such as cough, fever, shortness of breath or abdominal pain) were reviewed. It was assumed that the patient population remained largely the same throughout the study period (ie, predominantly patients who had family physicians but were unable to access them at the time of presentation $[17,18]$, which is essentially the same population that accessed the emergency department during weekends). The total numbers of patients presenting to the emergency department per month were obtained from the emergency department of the Janeway centre for comparison. Pediatric radiographs were used to avoid the potentially confounding lung findings common in adults.

Reports in which differentials included terms indicative of pneumonia (such as 'pneumonia', 'bronchopneumonia', 'consolidation', 'infiltrates' and 'airspace disease') were counted as positive (19). Qualifying terms were also noted, such as 'small', 'early' or 'extensive' in an effort to assess severity. Patients with radiographic evidence of pneumonia were excluded from the study on subsequent presentations due to the difficulty of distinguishing new pneumonias from residual changes.

Antibiotic prescription data for Newfoundland and Labrador were obtained from IMS Health Canada. The available data did not allow discrimination of antibiotics prescribed for pediatric patients from prescriptions written for adult patients. Data for typical pediatric respiratory antibiotics (cephalosporins, erythromycins, macrolides and penicillins) were combined to evaluate the effect of the strike on the availability of relevant antibiotics. It should be noted that these data represent the entire province of Newfoundland and Labrador during the month of October 2002, while the strike ended on October 17, and normal operations had resumed on October 20. As a result, these data overestimated the number of prescriptions written during the strike.

\section{RESULTS}

Pediatric respiratory antibiotic prescriptions fell province-wide by $16 \%$ during October 2002, relative to September 2002 and November 2002, and by 20\% relative to October 2001, a year that had generally lower antibiotic use (Figure 1). An estimate of the number of prescriptions projected to have been written in the absence of a strike was developed by calculating the average ratio between the two years (not including October 2002, the month of the strike) and then applying that ratio to the data from October 2001. Relative to this projection, the total number of prescriptions fell by $28 \%$ during October 2002. This is certainly an underestimation of the total change in antibiotic availability during the strike because the strike ended in the third week of October and the antibiotic data included the entire month.

In 2002, the total number of patients presenting to the Janeway emergency department increased from 2739 in September to 3477 in October, and then fell to 2951 during November, an increase during October of 22\%. Assuming that the final (poststrike) week of October had emergency room presentation rates similar to those of November, it was estimated that emergency room usage increased during the strike by approximately $28 \%$.

The total number of pediatric chest $\mathrm{x}$-rays performed for possible respiratory indications in the emergency department increased by $32 \%$ from 11.6 examinations per day before the strike to 16.4 per day during the strike and returned to an average of 13.9 per day following the strike. However, the number of chest radiographs taken during each day of the strike was not significantly different from the number of radiographs taken on the weekend days before and after the strike ( $t$ test, $\mathrm{P}>0.05$ ); the number of chest radiographs positive for pneumonia did not increase relative to pre- and poststrike weekend days ( $t$ test, $\mathrm{P}>0.05)$. The percentage of reports that included a differential diagnosis of pneumonia varied from $19 \%$ before the strike to $24 \%$ during and after the strike, with no statistically significant changes during the strike ( $z$ score, $\mathrm{P}>0.05$, Figure 2). Eight reports used the term 'extensive' to describe pneumonia extent, of which seven were from the strike period and one was immediately poststrike. Of these, seven were demonstrated to be resolving on follow-up radiographs or clinical records, while one was lost to follow-up.

\section{DISCUSSION}

Despite the physicians' strike, the volume of patients presenting with symptoms requiring a respiratory chest radiograph, 
and the number of positive radiographs, did not increase beyond those of a normal weekend day. There is no indication in these data of an increase in emergency room utilization beyond normal weekend rates. The entire strike period can perhaps be viewed as an extended 'weekend' pattern, when physicians' offices are closed and the emergency department has increased use.

There was no significant increase in the percentage of radiographically diagnosed pneumonias, despite a marked decrease in antibiotic availability. This supports the assertion that antibiotic availability in North America is much greater than that necessary to suppress respiratory disease. Had there been an increase in pneumonia due to the strike, one would expect an increased proportion of pneumonia presentations during the strike or during the week after the strike, neither of which occurred (Figure 2). Instead, there is no significant difference between the strike and nonstrike periods, and the data reflect both proportions (20) and seasonal trends found in other studies (21-23).

Eight radiology reports used the descriptive term 'extensive', seven of which were during the strike and one immediately after the strike. While this does not affect the prevalence of pediatric pneumonia, it does raise the possibility of an increase in severity during the strike, possibly because of delays in seeking medical attention due to perceived increased waiting times in the emergency department (24).

Several other factors may have affected these findings. There may have been an element of patient self-selection, with moderately unwell patients refraining from using the emergency room due to perceived long waiting periods (24). However, this would have increased the apparent incidence of pneumonia, and no such finding is demonstrated. Approximately 20\% of pneumonias are viral, especially among younger children, and thus they are not affected by the availability of antibiotics $(21,25)$; however, this baseline viral prevalence is not expected to change substantially and should not effect changes in overall incidence. Additionally, the incubation time of some pneumonia pathogens such as Mycoplasma pneumoniae is two to three weeks (26). It is possible that an increase in pneumonias may have become apparent had the strike continued; however, no clear pattern was emerging at the end of the strike and no increase was observed afterwards.

If antibiotics were appropriately prescribed, patients with clinical findings and symptoms suggestive of antibiotictreatable infections would receive antibiotics, while patients without these findings and symptoms would not. Antibiotic therapy would control the prevalence and course of respiratory tract infections and most respiratory infections would be nipped in the bud, never progressing to radiographically diagnosable pneumonias. Therefore a physicians' strike would decrease appropriately prescribed antibiotics, respiratory infections would progress unchecked and there would be an increase in the number of positive radiographs when patients presented to the emergency departments.

In our study, despite the fact that the ambient antibiotic level in the community fell by $28 \%$ or more, the prevalence of pneumonia in the pediatric population did not increase significantly. These data support the assertion that antibiotic levels are higher than necessary to keep a check on pediatric respiratory illness $(3,27)$. The simplest explanation for these data is that more antibiotics are prescribed than are required to control respiratory infection, and that these superfluous antibiotic

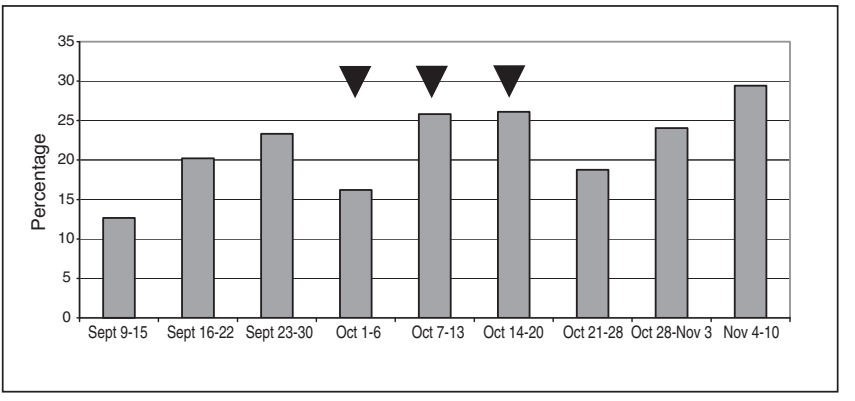

Figure 2) The percentage of pediatric emergency room radiographs reported as positive for pneumonia before, during (arrowheads) and after the physicians' strike of 2002. There is no statistically significant change between the strike period and the nonstrike period. Nov November; Oct October; Sept September

prescriptions accounted for most of the drop in prescriptions during the strike.

Prescribing practices of physicians are variable $(28,29)$, especially with respect to respiratory tract infections (3). Physicians and parents have divergent opinions about the role of antibiotics (30), and parental socioeconomic status $(31,32)$ and physician specialty $(29,32)$ have been shown to play a role in the decision as to which antibiotic, if any, is ultimately prescribed. During the strike, the unavailability of physicians outside of an emergency setting may have decreased the number of marginal or unnecessary prescriptions, while the continued availability of emergency room treatment allowed for treatment of patients for whom antibiotics were appropriate.

\section{REFERENCES}

1. Odenholt I, Bylander-Groth A, Fimodt-Moller N, Rokstad KS, Molstad S. Differences in antibiotic prescribing patterns between general practitioners in Scandinavia: A questionnaire study. Scand J Infect Dis 2002;34:602-9.

2. Bruinsma N, Hutchinson JM, van den Bogaard AE, Giamarellou H, Degener J, Stobberingh EE. Influence of population density on antibiotic resistance. J Antimicrob Chemother 2003;51:385-90.

3. Hutchinson JM, Foley RN. Method of physician remuneration and rates of antibiotic prescription. CMAJ 1999;160:1013-7.

4. Hutchinson JM, Jelinski S, Hefferton D, Desaulniers G, Parfrey PS. Role of diagnostic labeling in antibiotic prescription. Can Fam Physician 2001;47:1217-24.

5. Paluck E, Katzenstein D, Frankish CJ, et al. Prescribing practices and attitudes toward giving children antibiotics. Can Fam Physician 2001;47:521-7.

6. Mangione-Smith R, Elliot MN, Stivers T, McDonald L, Heritage J, McGlynn EA. Racial/ethnic variation in parent expectations for antibiotics: Implications for public health campaigns. Pediatrics 2004;113:e385-94.

7. Coenen S, Michiels B, Van Royen P, Van der Auwera JC, Denekens J. Antibiotics for coughing in general practice: A questionnaire study to quantify and condense the reasons for prescribing. BMC Fam Pract 2002;3:16.

8. Jain S, Sullivan K. Ceftriaxone use in the emergency department: Are we doing it right? Pediatr Emerg Care 2002;18:259-64.

9. McIsaac WJ, Goel V, To T, Low DE. The validity of a sore throat score in family practice. CMAJ 2000;163:811-5.

10. Perz JF, Craig AS, Coffey CS, et al. Changes in antibiotic prescribing for children after a community-wide campaign. JAMA 2002;287:3103-9.

11. Marcovici OA, Slater PE, Ellencweig AY. Effects of the Israel doctors' strike on hypertension control in Ashdod. Eur J Epidemiol 1987;3:30-4.

12. Bukovsky I, Herman A, Sherman D, Schreyer P, Arieli S, Caspi E. Perinatal outcome following physician's strike of 1983. Isr J Med Sci 1985;21:804-7. 
13. Aro S, Hosia P. Effects of a doctors' strike on primary care utilization in Varkaus, Finland. Scand J Prim Health Care 1987;5:245-51.

14. Steinherz R. Death rates and the 1983 doctors' strike in Israel. Lancet 1984;1:107.

15. Slater PE, Ever-Hadani P. Mortality in Jerusalem during the 1983 doctor's strike. Lancet 1983;2:1306.

16. James JJ. Impacts of the medical malpractice slowdown in Los Angeles County: January 1976. Am J Public Health 1979;69:437-43.

17. Grad R, Kaczorowski J, Singer Y, Levitt C, Mandelcorn J. Where do family practice patients go in case of emergency? Can Fam Physician 1998;44:2666-72.

18. Chan BT, Ovens HJ. Frequent users of emergency departments. Do they also use family physicians' services? Can Fam Physician 2002;48:1654-60.

19. Davies HD, Wang EE, Manson D, Babyn P, Shuckett B. Reliability of the chest radiograph in the diagnosis of lower respiratory infections in young children. Pediatr Infect Dis J 1996;15:600-4.

20. Rothrock SG, Green SM, Fanelli JM, Cruzen E, Costanzo KA, Pagane J. Do published guidelines predict pneumonia in children presenting to an urban ED? Pediatr Emerg Care 2001;17:240-3.

21. Lieberman D, Lieberman D, Porath A. Seasonal variation in community-acquired pneumonia. Eur Respir J 1996;9:2630-4.

22. Lieberman D, Lieberman D, Friger MD. Seasonal variation in hospital admissions for community-acquired pneumonia: A 5-year study. J Infect 1999;39:134-40.

23. Grant CC, Scragg R, Tan D, Pati A, Aickin R, Yee RL. Hospitalization for pneumonia in children in Auckland, New Zealand. J Paediatr Child Health 1998;34:355-9.
24. Ellencweig AY, Ginat-Israeli T. Effects of the Israel physicians' strike on the treatment and outcome of acute appendicitis in Jerusalem. Isr J Med Sci 1990;26:559-63.

25. McCracken GH Jr. Diagnosis and management of pneumonia in children. Pediatr Infect Dis J 2000;19:924-8.

26. Foy HM, Grayston JT, Kenny GE, Alexander ER, McMahan R. Epidemiology of Mycoplasma pneumoniae infection in families. JAMA 1966;197:859-66.

27. Wang EE, Einarson TR, Kellner JD, Conly JM. Antibiotic prescribing for Canadian preschool children: Evidence of overprescribing for viral respiratory infections. Clin Infect Dis 1999;29:155-60

28. Gaur AH, Hare ME, Shorr RI. Provider and practice characteristics associated with antibiotic use in children with presumed viral respiratory tract infections. Pediatrics 2005;115:635-41.

29. Rutschmann OT, Domino ME. Antibiotics for upper respiratory tract infections in ambulatory practice in the United States, 1997-1999: Does physician specialty matter? J Am Board Fam Pract 2004;17:196-200.

30. Bagshaw SM, Kellner JD. Beliefs and behaviours of parents regarding antibiotic use by children. Can J Infect Dis 2001;12:93-7.

31. Kozyrskyj AL, Carrie AG, Mazowita GB, Lix LM, Klassen TP, Law BJ. Decrease in antibiotic use among children in the 1990s: Not all antibiotics, not all children. CMAJ 2004;171:133-8.

32. Kozyrskyj AL, Dahl ME, Chateau DG, Mazowita GB, Klassen TP, Law BJ. Evidence-based prescribing of antibiotics for children: Role of socioeconomic status and physician characteristics. CMAJ 2004;171:139-45. 


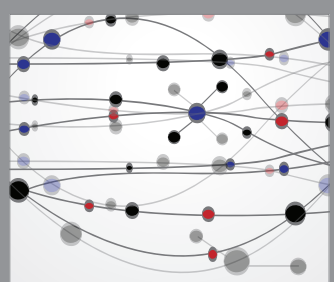

The Scientific World Journal
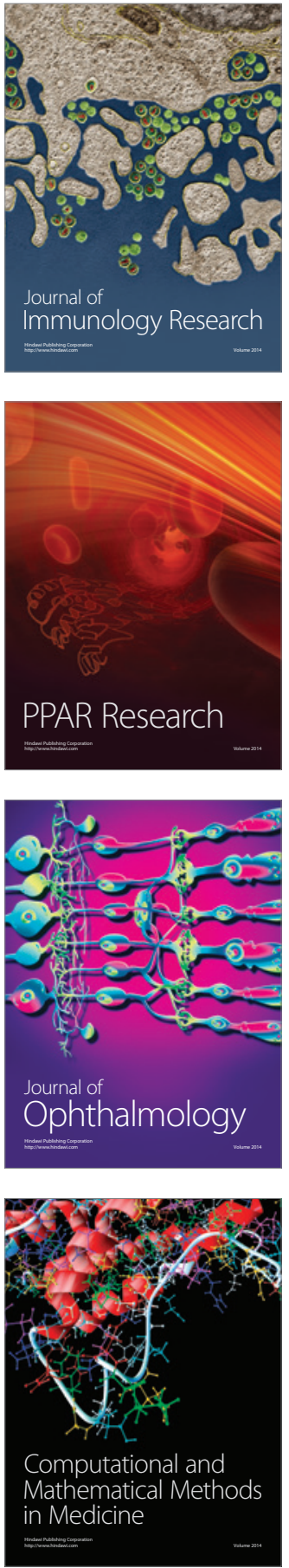

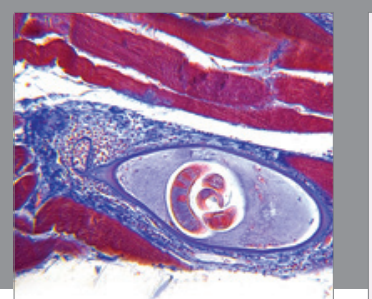

Gastroenterology Research and Practice

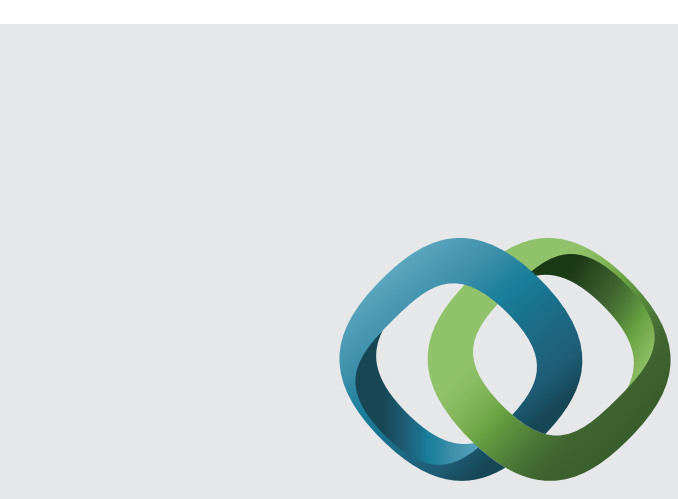

\section{Hindawi}

Submit your manuscripts at

http://www.hindawi.com
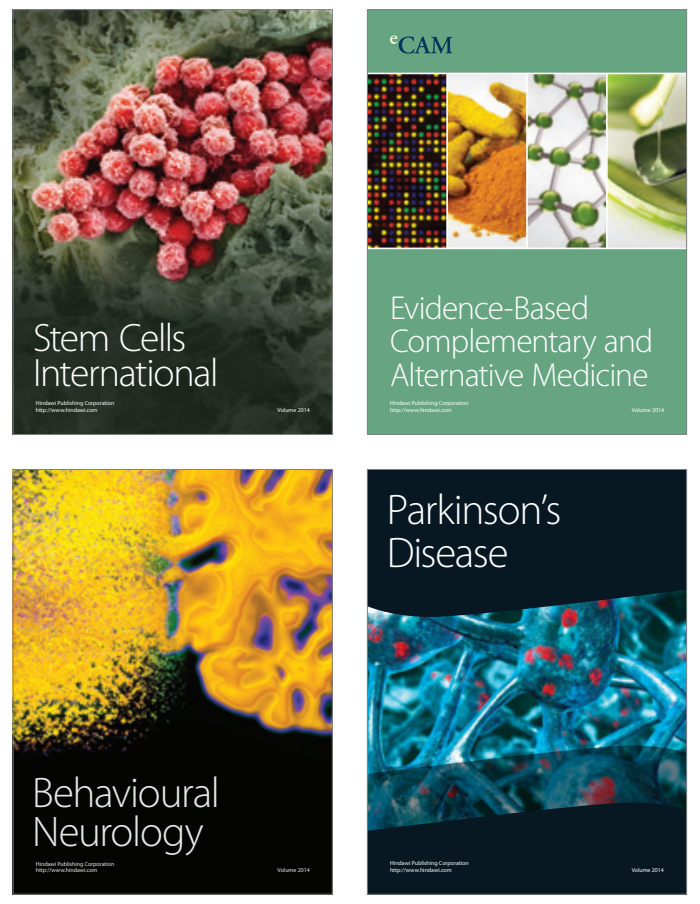
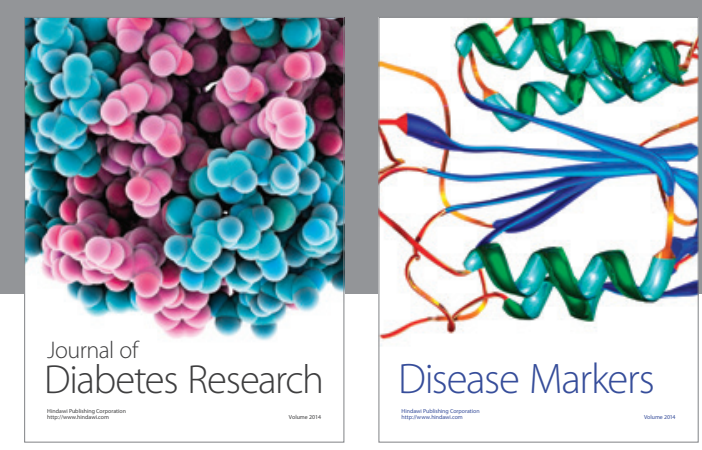

Disease Markers
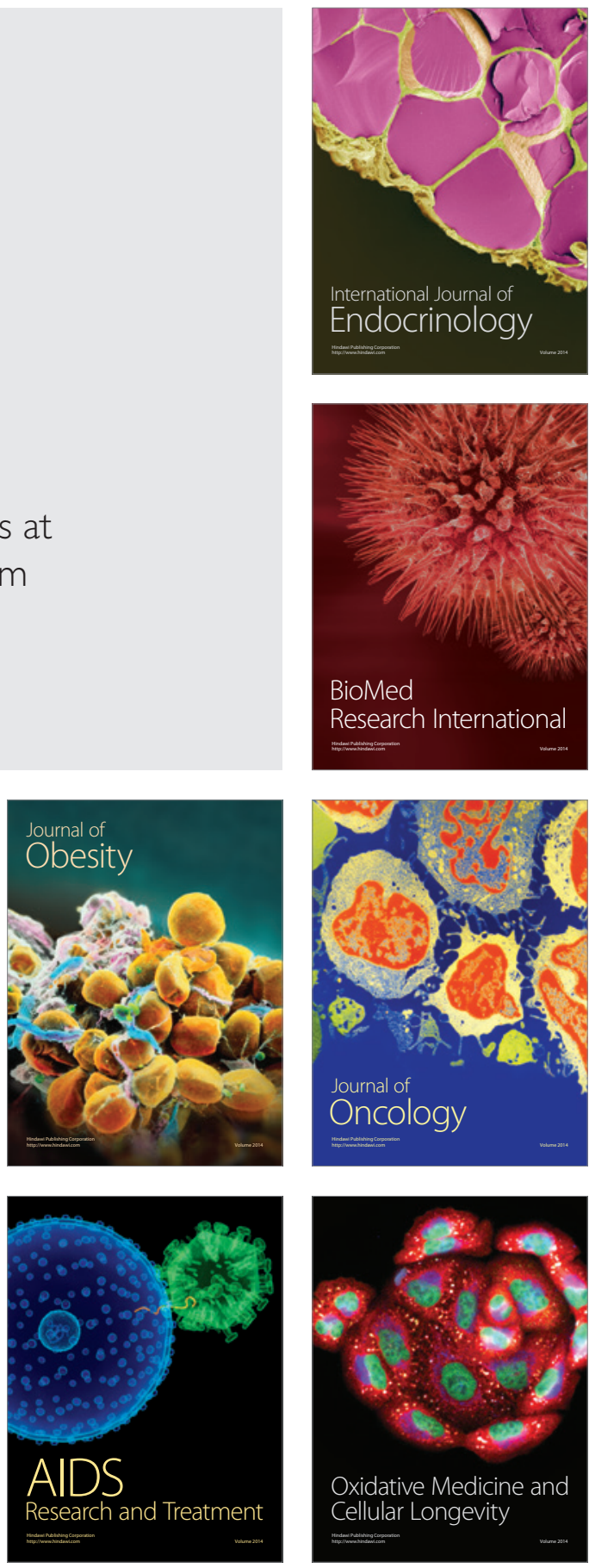